\title{
The Effect of Hemodialysis Treatment on Ventricular Arrhythmogenesis Parameters in Electrocardiography
}

\section{Hemodiyaliz Tedavisinin Elektrokardiyografide Ventriküler Aritmogenez Parametrelerine Etkisi}

Isa Ardahanli ${ }^{1}$,

Okan Akyuz ${ }^{2}$,

${ }^{1}$ Bilecik State Hospital, Department of Cardiology, Bilecik, Turkey

${ }^{2}$ Bilecik State Hospital, Department of Nephrology, Bilecik, Turkey

Geliş Tarihi/Received: 23 September 2020 Kabul Tarihi/Accepted: 25 November 2020

Address correspondence to: Isa Ardahanli, Bilecik State Hospital, Department of Cardiology, Bilecik, Turkey

ORCID

Isa Ardahanli

https://orcid.org/0000-0002-9309-803X

Okan Akyuz

https://orcid.org/0000-0003-2460-9577 e-mail: isaardahanli@gmail.com

\section{Öz}

Amaç: Hemodiyaliz (HD) hastalarında ventriküler aritmiler ve ani kardiyak ölüm (AKÖ) dahil kardiyovasküler olaylar birincil ölüm kaynağıdır. QT aralığı, QT dispersiyonu (QTd), TPe aralığı, TPe / QT oranı ve kardiyak-elektrofizyolojik denge (iCEB = QT / QRS) gibi EKG parametrelerinin kontrol edilmesi, yüksek aritmi ve SCD riski olan hastaların sınıflandırılmasında yararlı olabilir. Çalışmamız, HD seansı öncesi ve sonrasında elektrokardiyografik parametrelerdeki değişimi sağlıklı kontrol grubu ile karşılaştırmayı amaçladı.

Hastalar ve Yöntem: Çalışma Ocak 2020 ile Mart 2020 arasında 49 HD hastası ve 50 sağlıklı gönüllü dahil edilerek yapıldı. Gruplar hemodiyaliz ve kontrol grubu olarak iki gruba ayrıldı. Hemodiyaliz grubunun EKG'leri diyaliz öncesi ve sonrası değerlendirildi. EKG verileri tarandı ve dijital bir platformda değerlendirildi. QT, cQT, QTd, TPe, TPe / QT, TPe / cQT, QT / QRS ve cQT / QRS ölçüldü.

Bulgular: Hemodiyaliz sonrası QTd, cQTd, TPe, TPe / QTc ve QRS pre-HD'ye göre anlamlı olarak azalırken (her biri için $p<0,05$ ), diyaliz tedavisi sonrası HR, iCEB ve iCEBc anlamlı artış gösterdi $(p$ $<0,05$ için her biri). Diyaliz öncesi EKG parametreleri ile kontrol grubu karşılaştırıldığında QT, cQT, QTd, cQTd, TPe ve iCEBc pre-HD'de anlamlı olarak daha yüksekti (her biri için $\mathrm{p}<0.05$ ). Diyaliz sonrası EKG parametreleri karşılaştıııldığında, HR, CQT, QTd, CQTd, iCEB ve iCEBc değerleri kontrol grubuna göre of anlamlı olarak yüksekti (her biri için $\mathrm{p}<0.05$ ).

Sonuç: HD hastalarında ventriküler repolarizasyon ve depolarizasyonu birlikte gösteren elektrokardiyografik parametreler değerlendirilerek aritmi ve ani kardiyak ölüm riski öngörülebilir.

Anahtar Kelimeler: Elektrokardiyografi, ventriküler aritmi, hemodiyaliz

\section{Abstract}

Aim: Cardiovascular events, including ventricular arrhythmias and sudden cardiac death (SCD), are the primary source of death in hemodialysis (HD) patients. Checking ECG parameters such as QT interval, QT dispersion (QTd), TPe interval, TPe/QT ratio, and cardiac-electrophysiological balance (iCEB $=Q T / Q R S$ ) can be useful for classifying patients with high arrhythmia and SCD risk. Our study aimed to compare the change of electrocardiographic parameters before and after the HD session with the healthy control group.

Patients and Methods: The study was conducted between January 2020 and March 2020, including 49 HD patients and 50 healthy volunteers. The groups were divided into two groups as hemodialysis and control group. ECGs of the hemodialysis group were evaluated before and after dialysis. ECG data were scanned and evaluated on a digital platform. QT, cQT, QTd, TPe, TPe/QT, TPe/cQT, QT/QRS, and cQT/ QRS were measured.

Results: While QTd, cQTd, TPe, TPe / QTc, and QRS decreased significantly after hemodialysis compared to pre-HD( $p<0.05$ for each), HR, iCEB, and iCEBc showed a significant increase after dialysis treatment ( $p<0.05$ for each). Comparing pre-dialysis ECG parameters with the control group, QT, cQT, QTd, cQTd, TPe and iCEBc were significantly higher in pre-HD ( $p<0.05$ for each). Comparing the ECG parameters after dialysis, HR, cQT, QTd, cQTd, iCEB, and iCEBc values were significantly higher than the control group ( $\mathrm{p}<0.05$ for each).

Conclusion: By evaluating the electrocardiographic parameters showing ventricular repolarization and depolarization together, the risk of arrhythmia and sudden cardiac death can be predicted in HD patients

Key words: Electrocardiography, ventricular arrhythmia, hemodialysis

Cite this article as: Ardahanli I, Akyuz O. The Effect of Hemodialysis Treatment on Ventricular Arrhythmogenesis Parameters in Electrocardiography. Selcuk Med J 2021;37(1): 5-10

Disclosure: None of the authors has a financial interest in any of the products, devices, or drugs mentioned in this article. The research was not sponsored by an outside organization. All authors have agreed to allow full access to the primary data and to allow the journal to review the data if requested. 


\section{INTRODUCTION}

The most widely recognized reason for mortality in patients with end-stage renal failure (ESRD) receiving dialysis therapy is cardiovascular diseases (CVD) and its complications $(1,2)$. One of the reasons for this high cardiac mortality may be an increased frequency of sudden cardiac death (SCD) and sudden cardiac arrest (SCA) in hemodialysis (HD) patients. When the cardiac causes of deaths in dialysis patients worldwide are examined, there are large differences between countries. For example, 26\% of ESRDrelated deaths in Japan result from heart failure (HF) and only $2.5 \%$ from sudden deaths (3), while $28 \%$ of deaths in the United States of America are due to arrhythmia / cardiac arrest (4). SCD occurs due to ventricular arrhythmias developing due to cardiac conduction system disruption and repolarization anomalies, which is a multiplex and multifactorial process in which many accompanying pathologies (such as coronary artery disease, hypertrophic left ventricle, and fibrosis, disordered bone-mineral metabolism, plasma volume changes, acid-base, and electrolyte imbalance) also play a role (5).

The QT interval, QT dispersion (QTd), the T peakto-end (TPe) distance, TPe/QT ratio, and index of cardiac electrophysiological balance (QT/QRS ratio) (iCEB) are predicted ventricular repolarization. These parameters can indicate an increased risk of ventricular arrhythmia in ESRD $(6,7)$. Ions such as sodium, potassium, calcium, and magnesium have an essential role in providing depolarization and repolarization for a regular cardiac conduction system (8). In patients with renal failure, significant changes are seen in serum electrolytes due to reduced functions. The definitive and most effective treatment for patients with ESRD is renal transplantation. Unfortunately, due to inadequate organ donation and access to the transplanted center and some other social and economic reasons, kidney transplantation cannot be performed at the desired levels. Therefore, serum electrolytes' balance with an effective dialysis treatment in patients with ESRD is vital for the cardiac conduction system. Our study aimed to compare the changes in QT, cQT, QTd, TPe, TPe / QT, and iCEB measurements with dialysis treatment in ESRD patients. Also, we aimed to evaluate these parameters with the healthy control group.

\section{PATIENTS AND METHODS Study Design and Population}

This was a cross-sectional observational study.
Ninety-four patients diagnosed with ESRD who received $H D$ treatment in Bilecik Training and Research Hospital between January 2020 and March 2020 were evaluated. ECG evaluation of the patient group was assessed before (pre- HD) and after the dialysis session (post- HD). Forty-nine patients who remained after exclusion criteria were included in the study. The control group had 50 people who were age and sex-matched. Detailed medical histories of all participants were recorded, and a complete physical examination was applied. The demographic information of all participants was questioned, anthropometric measurements were performed and noted. Complete blood count and biochemical analysis were performed after 12 hours of fasting. Biochemically, renal function tests, liver function tests, thyroid functions, lipid profiles, CRP, bleeding profile values were measured. Besides, control renal function tests were evaluated after the dialysis session in the HD group. Informed written consent of all participants in the study were obtained. Approval was obtained from the Local Ethics Committee for the study (Number: 2020/016).

\section{Exclusion criteria:}

- Atrial fibrillation and history of known coronary artery disease

- Patients with pacemakers

- Patients with active infections

- With heart failure (LVEF< 50\%) and a history of antiarrhythmic drug use

- ECG evaluation cannot be made clear, among which $T$ wave cannot be measured clearly and $U$ wave in ECG

- Moderate or severe heart valve disease

- Those with a complete branch block

- $\mathrm{ktV}$ value $\leq 1.4$, those with hemodialysis time less than 4 hours

- Those with corrected serum calcium levels other than 8.5-10.2 meq / L

- Those without dialysate calcium $3.5 \mathrm{meq} / \mathrm{L}$ or 2meq / L

Electrocardiographic and echocardiographic evaluation

12-lead ECG was taken just before and after HD in the dialysis group and control group. The chest points to which the ECG leads were connected were marked with a colored marker, and the electrodes were connected to the same points after HD and the ECG recordings were repeated. ECG recordings were taken with Nihon Kohden (Tokyo, Japan) brand device in a supine position set at $10 \mathrm{~mm} / \mathrm{mV}$ voltage 
and $50 \mathrm{~mm} / \mathrm{s}$ paper speed. ECG was taken to the participants included in the study as a control group. All ECG recordings were done at least 10 minutes after rest and in a normal breathing pattern. The ECG strips were scanned and loaded into digital media, and the digital recordings were analyzed on the computer with an X300 \%magnification. Averages of values from 5 consecutive complexes of the V5 lead were used for measurements. All ECG measurements were also evaluated by two different cardiologists blinded to patient informations. The QT interval was defined as the distance from the start of the $Q$ wave to the end of the T wave. CQT was calculated based on heart rate by utilizing the Bazett formula (cQT = QT $\sqrt{ }(R R)$. Maximal (QTmax) and minimal (QTmin) QT intervals were characterized as the longest and shortest quantifiable QT wave times in any ECG lead, respectively. QTd calculated as QTmax minus QTmin. Tpe interval was defined by measuring the distance between the peak and the end of the $T$ wave. Then QT/QRS, cQT/QRS, TPe/QT, and TPe / cQT proportions were determined utilizing these estimations. Echocardiographic assessments were acted in the Cardiology Echocardiography Laboratory utilizing the EPIQ 7 (Philips, Amsterdam, Netherlands) echocardiography device. Echocardiographic measurements were made in the left lateral decupid position. Left ventricular wall thicknesses and other cardiac diameters were measured by parasternal long-axis imaging. LVEF was calculated using the modified Simpson method.

\section{Statistical analysis}

Statistical analysis was done by using SPSS software (version 22.0, SPSS Inc., Chicago, IL, US). Continuous variables are expressed as mean \pm standard deviation, while categorical variables are shown as frequency and percentage (\%). Quantitative data were evaluated for normality using the Kolmogorov-Smirnov and Shapiro-Wilk tests. According to the distribution of the data, groups were compared using Mann-Whitney $U$ or t-test. The Chisquare test was used to assess the distinctions of categorical variables between groups. In the statistical analysis obtained, a p-value below than 0.05 was considered significant.

\section{RESULTS}

Clinical features and anthropometric measurements of the HD patient group and control group are shown in Table 1 . The mean age in the study group was $66,128 \pm 11.58$. The average age distribution between the groups was similar $(p=0.901)$. The groups were similar in terms of risk factors such as HT, DM, and HL. Systolic blood pressure (SBP) was significantly higher in the HD group compared to the control group. Still, there was no significant difference between diastolic blood pressure (DBP) $(p<0.001$ and $p=0.636$, respectively). Although the left ventricular ejection fraction (LVEF) was high in the control group, this distinction was not measurably noteworthy ( $p$ $=0.105)$. Interventricular septum and posterior wall thicknesses were greater in the HD group (12.8 \pm 2.49 vs. $9.5 \pm 1.82$, and $13.1 \pm 2.36$ vs. $9.6 \pm 1.62$, respectively, $p<0.01$ for each).

The ECG comparison of the ESRD group before and after dialysis is shown in table 2. While QTd, cQTd, TPe, TPe / QTc, and QRS duration decreased significantly after hemodialysis compared to prehemodialysis ( $p<0.05$ for each), HR, iCEB, and iCEBc showed a significant increase after dialysis treatment ( $p<0.05$ for each). No significant change was observed in QT, cQT, TPe / QT. ( $p=0.384, p=$

Table 1. Demographic and anthropometric characteristics of the HD groups and controls.

\begin{tabular}{|c|c|c|c|}
\hline & HD (49) (Mean \pm SD) & Controls (50) (Mean \pm SD) & p-value \\
\hline Age (years) & $65.82 \pm 11.47$ & $66.74 \pm 12.02$ & 0.901 \\
\hline Gender (female /male) & $20 / 29$ & $24 / 26$ & 0.472 \\
\hline HT $(n, \%)$ & $27(55 \%)$ & $21(42 \%)$ & 0.192 \\
\hline $\mathrm{DM}(\mathrm{n}, \%)$ & $17(34.7)$ & $10(20 \%)$ & 0.101 \\
\hline $\mathrm{HL}(\mathrm{n}, \%)$ & $6(12.2 \%)$ & $8(16 \%)$ & 0.592 \\
\hline BMI $\left(\mathrm{kg} / \mathrm{m}^{2}\right)$ & $26.46 \pm 3.32$ & $28.68 \pm 2.9$ & 0.944 \\
\hline $\mathrm{SBP}(\mathrm{mm}-\mathrm{Hg})$ & $137.61 \pm 6,26$ & $124.72 \pm 10.32$ & $<0.001$ \\
\hline $\mathrm{DBP}(\mathrm{mm}-\mathrm{Hg})$ & $80.14 \pm 7.27$ & $77.66 \pm 7.08$ & 0.636 \\
\hline LVEF (\%) & $59.59 \pm 4.94$ & $62.56 \pm 5.48$ & 0.105 \\
\hline IVS (mm) & $12.8 \pm 2.49$ & $9.5 \pm 1.82$ & $<0.001$ \\
\hline $\mathrm{PW}(\mathrm{mm})$ & $13.1 \pm 2.36$ & $9.6 \pm 1.62$ & $<0.001$ \\
\hline GFR (mL/min) & $5.01 \pm 1.41$ & $94.31 \pm 12.31$ & $<0.001$ \\
\hline
\end{tabular}

HT: hypertension, DM: diabetes mellitus, HL: hyperlipidemia, BMI: body mass index, SBP: Systolic blood pressure, DBP: diastolic blood pressure, LVEF: left ventricular ejection fraction, IVS: interventricular septum, PW: posterior wall, GFR: glomerular filtration rate. 
Table 2. Electrocardiographic findings before and after hemodialysis.

\begin{tabular}{llll}
\hline Parameter & $\begin{array}{l}\text { Pre-HD } \\
\text { (Mean } \pm \text { SD) }\end{array}$ & $\begin{array}{l}\text { Post-HD } \\
\text { (Mean } \pm \text { SD) }\end{array}$ & p-value \\
\hline HR (beats/min) & $77.02 \pm 17.33$ & $84.94 \pm 18.62$ & 0.032 \\
QT (ms) & $384.46 \pm 34.20$ & $378.23 \pm 36.22$ & 0.384 \\
cQT (ms) & $422.57 \pm 16.17$ & $420.74 \pm 23.04$ & 0.649 \\
QTd (ms) & $31.49 \pm 5.46$ & $27.94 \pm 7.23$ & 0.007 \\
cQTd $(\mathrm{ms})$ & $32.21 \pm 6.76$ & $28.2865 \pm 9.44$ & 0.020 \\
TPe $(\mathrm{ms})$ & $74.39 \pm 10.09$ & $69.27 \pm 12.5$ & 0.028 \\
TPe/QT & $0.194 \pm 0.02$ & $0.183 \pm 0.03$ & 0.085 \\
TPe/cQT & $0.176 \pm 0.02$ & $0.164 \pm 0.02$ & 0.040 \\
QRS $(m s)$ & $98.14 \pm 12.28$ & $90.55 \pm 13.93$ & 0.005 \\
QT/QRS (iCEB) & $3.97 \pm 0.57$ & $4.24 \pm 0.62$ & 0.024 \\
cQT/QRS (iCEBc) & $4.36 \pm 0.53$ & $4.73 \pm 0.66$ & 0.003
\end{tabular}

HD: hemodialysis, HR: heart rate, iCEB: index of cardiac electrophysiological balance, iCEBc: index of cardiac electrophysiological balance with correction. The mean difference is significant at the 0.05 level.

0.649 ve $p=0.085$ respectively).

In comparison of pre-dialysis ECG parameters with the control group, HR $(p=0.841)$, TPe / QT $(p=$ $0.128)$, TPe / cQT $(p=0.381)$, QRS ( $p=0.7069)$ and iCEB ( $p=0.136)$ were similar, while QT, cQT, QTd, $c Q T d, T P e$ and iCEBc were significantly higher in preHD ( $p<0.05$ for each). The comparisons are shown in Table 3. In comparison of the ECG parameters after dialysis, HR, cQT, QTd, cQTd, iCEB and iCEBc values were significantly higher than the control group ( $p<0.05$ for each). QT $(p=0.057)$, TPe $(p=0.465)$ TPe / QT ( $p=0.750)$ and TPe / cQT (0.208) were similar. The comparisons are shown in Table 4.

\section{DISCUSSION}

In the study in which we evaluated ventricular repolarization parameters in chronic kidney disease (CKD) patients who received HD treatment, significant decreases were observed in QTd, cQTd, TPe, and QRS after dialysis treatment. In contrast, a significant increase was observed in QT/QRS (iCEB) values and HR. This was the first study that evaluated together many ECG parameters that could be used to determine ventricular arrhythmia in patients receiving HD treatment.

HD patients have an increased risk of SCD and SCA and are important causes of mortality (9). In a recent study, the increase in SCD in pre-HD was generally due to non-VF and bradyarrhythmia due to hyperkalemia. In contrast, post HD's risk increase was associated with fatal ventricular arrhythmia due to QT prolongation (10). Since there are many electrolyte changes and volume changes in HD sessions, this is expected to be reflected in the ECG. In the studies we have seen in the literature, there are different QT and CQT duration changes after hemodialysis. While most studies emphasized that the QT interval increased during or immediately after the HD session $(11,12)$, some different studies observed that HD had a neutral or even adverse effect $(6,13)$. Our study observed that there was no significant change in the QT interval with dialysis treatment, and what made our study different was the evaluation of QT dispersion. QTd and cQTd decreased significantly with dialysis

Table 3. Electrocardiographic findings between Pre-HD and control groups.

\begin{tabular}{llll}
\hline Parameter & $\begin{array}{l}\text { Pre-HD (49) } \\
\text { (Mean } \pm \text { SD) }\end{array}$ & $\begin{array}{l}\text { Controls (50) } \\
\text { (Mean } \pm \text { SD) }\end{array}$ & p-value \\
\hline HR (beats/min) & $77.02 \pm 17.33$ & $75.78 \pm 11.05$ & 0.841 \\
QT (ms) & $384.46 \pm 34.20$ & $365.89 \pm 26.83$ & 0.003 \\
cQT (ms) & $422.57 \pm 16.17$ & $394.86 \pm 20.04$ & $<0.001$ \\
QTd (ms) & $31.49 \pm 5.46$ & $22.66 \pm 9.04$ & $<0.001$ \\
cQTd (ms) & $32.21 \pm 6.76$ & $24.32 \pm 0.02$ & $<0.001$ \\
TPe & $74.39 \pm 10.09$ & $67.66 \pm 9.03$ & 0.001 \\
TPe/QT & $0.194 \pm 0.02$ & $0.185 \pm 0.03$ & 0.128 \\
TPe/cQT & $0.176 \pm 0.02$ & $0.171 \pm 0.03$ & 0.381 \\
QRS (ms) & $98.14 \pm 12.28$ & $99.30 \pm 16.74$ & 0.706 \\
QT/QRS (iCEB) & $3.97 \pm 0.57$ & $3.78 \pm 0.64$ & 0.136 \\
cQT/QRS (iCEBc) & $4.36 \pm 0.53$ & $4.08 \pm 0.69$ & 0.027 \\
\hline
\end{tabular}


Table 4. Electrocardiographic findings between post-HD and control groups.

\begin{tabular}{llll}
\hline Parameter & $\begin{array}{l}\text { Post-HD (49) } \\
\text { (Mean } \pm \text { SD) }\end{array}$ & $\begin{array}{l}\text { Control s (50) } \\
\text { (Mean } \pm \text { SD) }\end{array}$ & p-value \\
\hline HR (beats/min) & $84.94 \pm 18.62$ & $75.78 \pm 11.05$ & 0.004 \\
QT $(\mathrm{ms})$ & $378.23 \pm 36.22$ & $365.89 \pm 26.83$ & 0.570 \\
CQT $(\mathrm{ms})$ & $420.74 \pm 23.04$ & $394.86 \pm 20.04$ & $<0.001$ \\
QTd $(\mathrm{ms})$ & $27.94 \pm 7.23$ & $22.66 \pm 9.04$ & $<0.001$ \\
cQTd $(\mathrm{ms})$ & $28.2865 \pm 9.44$ & $24.32 \pm 0.02$ & $<0.001$ \\
$\mathrm{TPe}(\mathrm{ms})$ & $69.27 \pm 12.5$ & $67.66 \pm 9.03$ & 0.465 \\
$\mathrm{TPe} / \mathrm{QT}$ & $0.183 \pm 0.03$ & $0.185 \pm 0.03$ & 0.750 \\
$\mathrm{TPe} / \mathrm{cQT}$ & $0.164 \pm 0.02$ & $0.171 \pm 0.03$ & 0.208 \\
QRS $(\mathrm{ms})$ & $90.55 \pm 13.93$ & $99.30 \pm 16.74$ & 0.008 \\
QT/QRS (iCEB) & $4.24 \pm 0.62$ & $3.78 \pm 0.64$ & $<0.001$ \\
cQT/QRS (iCEBc) & $4.73 \pm 0.66$ & $4.08 \pm 0.69$ & $<0.001$ \\
\hline
\end{tabular}

treatment. Also, this significant difference in QTd was striking in the comparison of pre-dialysis and healthy control groups. In surface 12-lead electrocardiography (ECG), the absolute difference between the longest (maximum) QT duration and the shortest (minimum) QT duration is defined as QT dispersion. Today, it is accepted that QT dispersion is linked to the regional heterogeneity of ventricular repolarization and thus indicates the electrical instability of the myocardium, as is the prolongation of the QT timeThe shortening of the QT dispersion in our findings suggests that an effective HD may decrease the susceptibility to arrhythmogenesis in CKD patients receiving dialysis treatment.

TPe interval is the distance between the peak and the end of the $T$ wave and shows ventricular repolarization (14). Besides, parameters obtained by the ratio to QT (TPe/QT and TPe/cQT) have been delivered better to predict ventricular repolarization dispersion $(15,16)$. It has been shown in many studies that the increase in TPe is associated with arrhythmias and mortality (17-20). Since the TPe range is affected by the variability of body surface area and heart rate, the TPe / QT and TPe / cQT ratios are considered more significant than the TPe range because they are not affected by these variables (16). An increase in TPe/QT ratio and TPe in ESRD patients has been shown to increase compared to the healthy control group $(6,21)$. There were significantly higher TPe values before HD than after HDIt was similar between the post-HD and control groups in our study. We think that the possible physiological explanation for this situation may be that serum electrolytes, which play a role in myocardial contraction, become similar to healthy person levels with dialysis. Another difference from these studies is that in our result, TPe / QT ratio is similar between the groups. The results we obtained here, different from the literature, maybe that the hemodialysis patient group we included in the study was all patients who met the adequate hemodialysis criteria and were more stable in terms of hemodynamic and biochemical parameters. As a reason, we think that our study contributed to patients who meet the requirements of adequate and effective hemodialysis with a $\mathrm{ktV}$ value of 1.4 and above. We believe that cardiac events can be reduced in hemodialysis patients using appropriate, sufficient time, and proper dialysate solutions. ESRD patients have highly variable levels in terms of serum electrolytes. Dialysis procedure is the treatment modality that can disrupt hemodynamics very quickly to carry this disorder to physiological limits. It is no surprise that these sudden electrolyte changes cause cardiac arrhythmias. Therefore, we think it is vital to prevent dialysis duration and the premature deterioration of patients' hemodynamics, especially in patients with cardiac disease undergoing hemodialysis.

The QT/QRS ratio, also known as the iCEB, is a noninvasive parameter that provides knowledge about myocyte action potential's repolarization and depolarization phase. These aspects show both phases, it can better show the proarrhythmic risk than QT interval (22). While increased iCEB is associated with Torsades, decreased values are related to nonTorsades ventricular tachycardia and ventricular fibrillation (23). In some studies, iCEB has been shown to have a prognostic value in some diseases $(24,25)$. A recent study in ESRD patients found that iCEB was significantly higher in HD patients than the control group, and a significant increase was reported before and after HD. (26). We also obtained findings similar to this study in the iCEB evaluation. However, there is no widely accepted reference range for iCEB, which is thought to be an arrhythmogenesis predictor. 
Robins et al suggested a preliminary reference interval of 3.14 to 5.35 . This reference range can be verified or modified by future comprehensive and multi-participant studies. Our study's main limitation was the relatively low number of patients and the crossectional design of the study. Long-term followup with rhythm holter may be more useful in detecting ventricular arrhythmias in these patients. We think that more extensive prospective research is needed to demonstrate the collation between the ECG parameters' arrhythmic events mentioned in these patient groups.

As a result, we think that the risk of arrhythmia and sudden cardiac death can be estimated by evaluating electrocardiographic parameters that show ventricular repolarization and depolarization together in HD patients.

Conflict of interest: Authors declare that there is no conflict of interest between the authors of the article.

Financial conflict of interest: Authors declare that they did not receive any financial support in this study.

Address correspondence to: Isa Ardahanli, Bilecik State Hospital, Department of Cardiology, Bilecik, Turkey

E-mail: isaardahanli@gmail.com

Phone number: +905335768325

\section{REFERENCES}

1. Pilmore H, Dogra G, Roberts M, et al. Cardiovascular disease in patients with chronic kidney disease. Nephrology (Carlton) 2014;19(1):3-10.

2. Collins AJ, Foley RN, Gilbertson DT, et al. United states renal data system public health surveillance of chronic kidney disease and end-stage renal disease. Kidney Int Suppl (2011) 2015;5(1):2-7

3. Hanafusa N, Nakai S, Iseki K, et al. Japanese society for dialysis therapy renal data registry-a window through which we can view the details of Japanese dialysis population. Kidney Int Suppl (2011) 2015;5(1):15-22.

4. Saran R, Li Y, Robinson B, et al. US Renal data system 2015 annual data report: Epidemiology of Kidney Disease in the United States. Am J Kidney Dis 2016;67(3 Suppl 1):Svii-S305.

5. Mozos I. Laboratory markers of ventricular arrhythmia risk in renal failure. Biomed Res Int 2014;2014:509204.

6. Kalantzi K, Gouva C, Letsas KP, et al. The impact of hemodialysis on the dispersion of ventricular repolarization. Pacing Clin Electrophysiol 2013;36(3):322-7.

7. Waks JW, Tereshchenko LG, Parekh RS. Electrocardiographic predictors of mortality and sudden cardiac death in patients with end stage renal disease on hemodialysis. J Electrocardiol 2016;49(6):848-54.

8. Weiss JN, Qu Z, Shivkumar K. Electrophysiology of hypokalemia and hyperkalemia. Circ Arrhythm Electrophysiol 2017;10(3):e004667.

9. Green D, Roberts PR, New DI, et al. Sudden cardiac death in hemodialysis patients: An in-depth review. Am J Kidney Dis 2011;57(6):921-9.

10. Joki N, Tokumoto M, Takahashi N, et al. Current perspectives on sudden cardiac death in hemodialysis patients. Contrib Nephrol 2018;196:5-12

11. Sohal PM, Goel A, Gupta D, et al. Effect of hemodialysis on corrected QT interval and CQT dispersion. Indian J Nephrol 2018;28(5):335-8.

12. Genovesi S, Rossi E, Nava M, et al. A case series of chronic haemodialysis patients: Mortality, sudden death, and QT interval. Europace 2013;15(7):1025-33.

13. Astan R, Akpinar I, Karan AE, et al. The effect of hemodialysis on electrocardiographic parameters. Ann Noninvasive Electrocardiol 2015;20(3):253-7.

14. Kors JA, Ritsema van Eck HJ, van Herpen G. The meaning of the Tp-Te interval and its diagnostic value. J Electrocardiol 2008;41(6):575-80.

15. Kaplan O, Kurtoglu E, Nar G, et al. Evaluation of electrocardiographic T-peak to T-end interval in subjects with increased epicardial fat tissue thickness. Arq Bras Cardiol 2015;105(6):566-72.

16. Gupta $P$, Patel $C$, Patel $H$, et al. T(p-e)/QT ratio as an index of arrhythmogenesis. J Electrocardiol 2008;41(6):567-74.

17. Erikssen G, Liestø| K, Gullestad L, et al. The terminal part of the QT interval (T peak to $T$ end): A predictor of mortality after acute myocardial infarction. Ann Noninvasive Electrocardiol 2012;17(2):85-94.

18. Tse G, Gong M, Li CKH, et al. Tpeak-Tend, Tpeak-Tend/QT ratio and Tpeak-Tend dispersion for risk stratification in Brugada Syndrome: A systematic review and meta-analysis. J Arrhythm 2018;34(6):587-97.

19. Sökmen E, Özbek SC, Çelik M, et al. Changes in the parameters of ventricular repolarization during preapnea, apnea, and postapnea periods in patients with obstructive sleep apnea. Pacing Clin Electrophysiol 2018;41(7):762-6.

20. Ardahanli I, Celik M. Comparison of Tp-e interval, QTc interval and Tp-e/QTc ratios between non-diabetic and prediabetic population. Ann Med Res 2020;27(12):3117-22.

21. Jaroszyński AJ, Załuska WT, Ksiazek A. Effect of haemodialysis on regional and transmural inhomogeneities of the ventricular repolarisation phase. Nephron Clin Pract 2005;99(1):c24-c30.

22. Robyns T, Lu HR, Gallacher DJ, et al. Evaluation of index of cardio-electrophysiological balance (iCEB) as a new biomarker for the identification of patients at increased arrhythmic risk. Ann Noninvasive Electrocardiol 2016;21(3):294-304.

23. Lu HR, Yan GX, Gallacher DJ. A new biomarker--index of cardiac electrophysiological balance (iCEB)--plays an important role in drug-induced cardiac arrhythmias: beyond QT-prolongation and Torsades de Pointes (TdPs). J Pharmacol Toxicol Methods 2013;68(2):250-9.

24. Nafakhi H, Al-Mosawi AA, Alareedh M, et al. Index of cardiac electrophysiological balance and transmural dispersion of the repolarization index relationships with pericardial fat volume and coronary calcification. Biomark Med 2018;12(4):321-8.

25. Hemmeryckx B, Feng Y, Frederix L, et al. Evaluation of cardiac arrhythmic risks using a rabbit model of left ventricular systolic dysfunction. Eur J Pharmacol 2018;832:145-55.

26. SivriS, ÇelikM. Evaluation of index of cardiac-electrophysiological balance before and after hemodialysis in patients with end-stage renal disease. J Electrocardiol 2019;54:72-5. 